\title{
Comprehensive Review of Complete Versus Culprit-only Revascularization for Multivessel Disease in ST-segment Elevation Myocardial Infarction
}

\author{
Robin Jacob, ${ }^{1}$ Ayaaz K Sachedina ${ }^{2}$ and Sachin Kumar ${ }^{1}$ \\ 1. Division of Cardiology, University of Texas Health Science Center at Houston, TX, USA; 2. Libin Cardiovascular Institute, University of \\ Calgary, Calgary, Alberta, Canada
}

DOI: https://doi.org/10.17925/HI.2021.15.1.54

\begin{abstract}
$\mathrm{S}$ everal organizations have developed guidelines for the management of ST-segment elevation myocardial infarction (STEMI). However, the optimal strategy regarding revascularization in the setting of multivessel disease, specifically with regards to culprit vessel versus complete revascularization, continues to evolve. While previous observational studies promoted culprit vessel-only intervention in patients with STEMI, recent randomized controlled trials suggest potential benefits with multivessel revascularization, either at the time of the index event or in a staged fashion, in patients without cardiogenic shock. This may be due to the known instability of non-culprit lesions in the setting of acute coronary syndrome, and the diffuse coronary processes involved. As additional literature examines culprit vessel versus multivessel revascularization strategies, clinicians continue to be tasked with determining optimal treatment plans for their patients and understanding the factors that promote selected revascularization strategies. This review summarizes and discusses observational studies, randomized control trials and current guidelines in order to evaluate optimal reperfusion strategies for patients presenting with STEMI in the setting of multivessel disease.
\end{abstract}

\section{Keywords}

ST-segment elevation myocardial infarction, acute coronary syndrome, complete revascularization, multivessel revascularization, culprit vessel-only revascularization

Disclosure: Robin Jacob, Ayaaz Sachedina, and Sachin Kumar have no financial or non-financial relationships or activities to declare in relation to this article.

Review process: Double-blind peer review.

Compliance with ethics: This study involves a review of the literature and did not involve any studies with human or animal subjects performed by any of the authors.

Authorship: All named authors meet the criteria of the International Committee of Medical Journal Editors for authorship for this manuscript, take responsibility for the integrity of the work as a whole and have given final approval for the version to be published.

Access: This article is freely accessible at

touchCARDIO.com (C) Touch Medical Media 2021

Received: 4 December 2020

Accepted: 5 July 2021

Published online: 2 August 2021

Citation: Heart International. 2021;15(1):54-9

Corresponding author: Sachin Kumar, Memorial Hermann Medical Center, McGovern Medical School, University of Texas Health Science Center, Houston, TX 77030, USA. E: Sachin.kumar@uth.tmc.edu

Support: No funding was received for the publication of this article.
Multivessel disease is common amongst patients presenting with ST-segment elevation myocardial infarction (STEMI). Previous studies have shown that up to $40-65 \%$ of patients presenting with STEMI have multivessel disease. ' Pooled analyses of STEMI trials from the fibrinolytic and percutaneous coronary intervention $(\mathrm{PCl}$ ) eras reveal that the presence of obstructive multivessel disease has been associated with worse outcomes, including recurrent angina, repeat revascularization and higher mortality. ${ }^{1.2}$ Although $\mathrm{PCl}$ of only the culprit lesion in STEMI is a common revascularization strategy, there remains variable approaches regarding reperfusion strategies in the setting of multivessel disease. Multiple theoretical assumptions exist regarding the higher mortality rates noted in patients with obstructive multivessel disease, including greater burden of co-morbid conditions, accompanied haemodynamic perturbations, higher residual ischaemic milieu, endothelial dysfunction and inflammation. Despite its common occurrence, there has been a relative paucity of randomized studies regarding the management of significant stenoses in the non-infarct arterial territories until recently. Management options often depend on the haemodynamic stability of the patient, and can include culprit vessel only (CVO) PCl with medical therapy for all other non-culprit lesions; multivessel revascularization at the time of index procedure (complete multivessel intervention [CVI]); $\mathrm{PCl}$ of the culprit lesion followed by staged revascularization of non-culprit lesions (CVI-S); or PCl of the culprit lesion followed by planned, staged $\mathrm{PCl}$ of the non-culprit vessels if there are residual symptoms or evidence of ischaemia on non-invasive stress testing.

The pathophysiology and associated clinical outcomes of non-culprit lesions in the setting of STEMI are important considerations when deciding a revascularization strategy. Several studies have shown that non-culprit lesions in an acute coronary syndrome (ACS) setting are unstable, with similar morphologic characteristics of culprit lesions, as seen by angiography, intravascular ultrasound and angioscopy. ${ }^{3-5}$ Although these findings have not been studied for major clinical significance, it is evident that the prognosis is worse for patients with multivessel disease and STEMI. This may be due to older age, more atherosclerotic risk factors, greater ischaemic burden and lower left ventricular ejection fraction. ${ }^{\circ}$ In this review, where medical literature databases were searched, we aimed to summarize and discuss the current literature examining multivessel disease in STEMI in order to fully evaluate optimal reperfusion strategies for these patients, and provide guidance to treating physicians. 
Table 1: Observational analyses on culprit vessel percutaneous coronary intervention versus multivessel revascularization

\begin{tabular}{|c|c|c|c|c|c|c|}
\hline Authors and reference & $\begin{array}{l}\text { Registry and } \\
\text { recruitment } \\
\text { years }\end{array}$ & $\begin{array}{l}\text { Culprit } \\
\text { vessel PCl } \\
\text { (CVO), } \mathrm{n}\end{array}$ & $\begin{array}{l}\text { Multivessel } \\
\text { revascularization } \\
(\mathrm{CVI}), \mathrm{n}\end{array}$ & Primary endpoint & Follow up & Results \\
\hline Hannan et al., $2010^{10}$ & $\begin{array}{l}\text { PCIRS registry, } \\
\text { multicentre, } \\
\text { 2003-2006 }\end{array}$ & 503 & 503 & In-hospital mortality & Index hospitalization & $\begin{array}{l}0.9 \% \text { for } \mathrm{CVO} P C l \text { versus } 2.4 \% \\
\text { for } \mathrm{CVI}, \mathrm{p}=0.04\end{array}$ \\
\hline Iqbal et al., $2014^{9}$ & $\begin{array}{l}\text { London registry, } \\
\text { multicentre, } \\
\text { 2004-2011 }\end{array}$ & 3,429 & 555 & $\begin{array}{l}\text { In-hospital reinfarction, } \\
\text { revascularization, CVA and } \\
\text { mortality }\end{array}$ & Index hospitalization & $\begin{array}{l}4.6 \% \mathrm{MACE} \text { for } \mathrm{CVO} \mathrm{PCl} \\
\text { versus } 7.2 \% \text { for } \mathrm{CVI}, \mathrm{p}=0.01\end{array}$ \\
\hline Jaguszewski et al., 201377 & $\begin{array}{l}\text { AMIS Plus } \\
\text { registry, } \\
\text { 2005-2012 }\end{array}$ & 3,833 & 1,108 & In-hospital mortality & Index hospitalization & $\begin{array}{l}4.4 \% \text { for } \mathrm{CVO} P C \mathrm{Pl} \text { versus } 7.3 \% \\
\text { for } \mathrm{CVI}, \mathrm{p}<0.001\end{array}$ \\
\hline Abe et al., 2014 ${ }^{11}$ & $\begin{array}{l}\text { Ibaraki registry, } \\
\text { 2007-2010 }\end{array}$ & 220 & 54 & $\begin{array}{l}\text { All cause death, } \mathrm{Ml} \text {, } \\
\text { revascularization and CVA }\end{array}$ & 374 days & $\begin{array}{l}27.7 \% \mathrm{MACE} \text { in CVO PCl } \\
\text { versus } 46 \% \text { in } \mathrm{CVI}, \mathrm{p}<0.05\end{array}$ \\
\hline Santos et al., $2014^{8}$ & $\begin{array}{l}\text { Portuguese } \\
\text { registry, } \\
\text { 2010-2011 }\end{array}$ & 180 & 77 & In-hospital mortality & Index hospitalization & $\begin{array}{l}7.8 \% \text { for } \mathrm{CVO} \text { PCI versus } 2.6 \% \\
\text { for } \mathrm{CVI}, \mathrm{p}>0.05\end{array}$ \\
\hline Lee et al., 2018 & $\begin{array}{l}\text { KAMIR-NIH } \\
\text { registry, } \\
\text { 2011-2015 }\end{array}$ & 399 & 260 & 1-year all-cause death & 1 year & $\begin{array}{l}32 \% \mathrm{CVO} P \mathrm{PCl} \text { versus } 21 \% \text { for } \\
\mathrm{CVI}, \mathrm{p}=0.001\end{array}$ \\
\hline
\end{tabular}

AMIS = Acute Myocardial Infarction in Switzerland; CVA = cerebrovascular insufficiency; $C V I=$ complete multivessel intervention; $C$ VO = culprit vessel only;

KAMIR-NIH = The Korea Acute Myocardial Infarction Registry-National Institutes of Health; $\mathrm{MACE}=$ major adverse cardiac events; $\mathrm{MI}=$ myocardial infarction; $P C I=$ percutaneous coronary intervention; PCIRS = New York's State's Percutaneous Coronary Interventions Reporting System.

\section{Observational trials}

Over the past decade, there have been several observational studies that have compared $\mathrm{CVO} \mathrm{PCl}$ to multivessel $\mathrm{PCl}$, either in a staged fashion or at the index event (Table 1). ${ }^{7-12}$ Cavender et al. evaluated data from a large, multicentre, national registry (National Cardiovascular Data Registry, $n=708,481$ ), and compared a patient group with multivessel $\mathrm{PCl}$ in a STEMI setting to one undergoing CVO. ${ }^{13}$ Endpoints included in-hospital mortality and complications associated with the procedure. The authors concluded that unadjusted in-hospital risk of mortality (7.85\% versus $5.12 \%, p<0.01)$ and bleeding complications $(6.71 \%$ versus $5.3 \%, p<0.01$ ) were higher in patients who underwent $\mathrm{CVI}$ compared with patients treated with CVO.

The Swiss AMIS Plus registry examined a similar cohort, and attempted to identify patients with STEMI requiring multivessel $\mathrm{PCl} .{ }^{\text {T They found that }}$ patients with left main disease, out-of-hospital cardiac arrest, and who were Killip class III/IV and received CVI had higher inpatient mortality when compared with those who received CVO (7.3\% versus $4.4 \%$; $\mathrm{p}<0.001)$. However, when the mortality analysis was performed, after risk adjustment of the patient cohort, mortality estimates were comparable. Similarly, a registry from 2014 found no in-hospital mortality difference between $\mathrm{CVO} \mathrm{PCl}$ and multivessel revascularization for patients with STEMI with multivessel disease. ${ }^{8}$

The London Heart Attack Centre investigators looked to evaluate predictors of inpatient mortality and all-cause mortality in patients with STEMI with multivessel involvement across eight centres in London. ${ }^{9}$ Among 3,984 patients with propensity score matching, CVO was favourably associated with reduced in-hospital events and death, as well as improved outcomes at 1 year. Inpatient major adverse cardiac events (MACE) (4.6\% versus 7,2\%, p=0.010) and mortality at 1 year $(7.4 \%$ versus $10.1 \% ; p=0.031$ ) were significantly lower in the CVO cohort. Researchers at the University of Ottawa Heart Institute evaluated this strategy in 1,038 patients, with a primary aim to look at mortality outcomes at 6 months and associated covariates of in-hospital outcomes as well. ${ }^{14}$ 180-day mortality among patients with CVI-S and CVO was significantly different at baseline $(0.8 \%$ versus $5 \%, p=0.003)$, favouring CVI-S, and this persisted after adjustment of baseline characteristics.

Multiple other studies have evaluated the same paradigm in the setting of complete revascularization of the non-culprit vessels in a staged fashion, with intervention completed predominantly out of the hospital at variable lengths of time from the index event. A single-centre, observational analysis from Taiwan studied patients undergoing STEMI with single-vessel disease versus STEMI with multivessel involvement treated with strategies of CVO and CVI-S fashion. ${ }^{15}$ The staged revascularization of the non-infarct artery was performed within 6 months of the index event. Data revealed higher mortality and lower successful reperfusion in patients with multivessel involvement, which has been reliably reproduced. Among the sub-group with multivessel disease, those treated with a CVO strategy did worse compared with those treated with staged complete revascularization. Additional studies by Toyota et al. (the CREDO Kyoto investigators) and Manari et al. also examined revascularization strategies in acute myocardial infarction (MI). 16,17 While patients with left main disease, haemodynamic instability and chronic total occlusions were excluded, the overall analyses suggested increased mortality at 30-60 days in patients with acute MI and a CVO $\mathrm{PCl}$ strategy. ${ }^{16,18}$

\section{Limitations of observational studies}

The previously mentioned observational studies all have limitations inherent to registry-based analyses. Large differences in samples sizes and follow-up periods between studies, ranging anywhere from 50 to 4,000 patients, and from index hospitalization up to multiple years, likely contribute to the differing results of these studies. Although most studies involved only patients with STEMI, some studies' inclusion criteria included those with non-ST segment elevation (NSTEMI) as well. In addition, exclusion criteria differed amongst the studies, with many excluding cardiogenic shock. Different trials also varied in their definitions of significant coronary lesions. While some trials considered 
Table 2: Randomized controlled trials on culprit vessel percutaneous coronary intervention versus multivessel revascularization

\begin{tabular}{|c|c|c|c|c|c|c|c|}
\hline $\begin{array}{l}\text { Authors and } \\
\text { reference }\end{array}$ & Study & $\begin{array}{l}\text { Culprit } \\
\text { vessel PCl } \\
\text { (CVO), n }\end{array}$ & $\begin{array}{l}\text { Multivessel } \\
\text { primary } \\
\mathrm{PCl}(\mathrm{CVI}), \mathrm{n}\end{array}$ & $\begin{array}{l}\text { Multivessel } \\
\text { staged } \mathrm{PCl} \\
\text { (CVI-S), } \mathrm{n}\end{array}$ & $\begin{array}{l}\text { Primary endpoint, } \\
\text { MACE }\end{array}$ & Follow up & Results \\
\hline $\begin{array}{l}\text { Di Mario et al., } \\
2004^{19}\end{array}$ & HELP AMI & 17 & 52 & $\mathrm{~N} / \mathrm{A}$ & $\begin{array}{l}\text { Repeat } \\
\text { revascularization }\end{array}$ & 12 months & $\begin{array}{l}35 \% \text { in } \mathrm{CVO} \mathrm{PCl} \text { versus } 17 \% \mathrm{CVI} \text {, } \\
\mathrm{p}=0.247\end{array}$ \\
\hline $\begin{array}{l}\text { Politi et al., } \\
2010^{18}\end{array}$ & Multicentre & 84 & 65 & 65 & $\begin{array}{l}\text { MI, death, TVR, repeat } \\
\text { hospitalization for ACS }\end{array}$ & Mean 2.5 years & $\begin{array}{l}50 \% \text { MACE in CVO PCI versus } 20 \% \\
\text { (CVI-S) group and } 23 \% \text { in CVI, } p<0.001\end{array}$ \\
\hline $\begin{array}{l}\text { Ghani et al., } \\
2012^{23}\end{array}$ & Single-centre & 41 & 80 & N/A & Ml, death, TVR & 3 years & $\begin{array}{l}35 \% \text { MACE in CVO PCl versus } 35.4 \% \\
\text { in } 35 \%, C V I p=0.96\end{array}$ \\
\hline $\begin{array}{l}\text { Wald et al., } \\
2013^{20}\end{array}$ & PRAMI & 231 & 234 & N/A & $\mathrm{MI}, \mathrm{CV}$ death, angina & 23 months & $\begin{array}{l}23 \% \mathrm{MACE} \text { in CVO PCI versus } 9 \% \text { in } \\
\mathrm{CVI}, \mathrm{p}<0.001\end{array}$ \\
\hline $\begin{array}{l}\text { Hlinomaz et al., } \\
2015^{21}\end{array}$ & PRAGUE-13 & 108 & N/A & 106 & Ml, death, CVA & 38 months & $\begin{array}{l}13.9 \% \mathrm{MACE} \text { in CVO PCI versus } 16 \% \\
\text { in CVI-S, } \mathrm{p}=0.41\end{array}$ \\
\hline $\begin{array}{l}\text { Engstrøm et al., } \\
2015^{24}\end{array}$ & $\begin{array}{l}\text { DANAMI3- } \\
\text { PRIMULTI }\end{array}$ & 313 & 314 & N/A & MI, death, TVR & 27 months & $\begin{array}{l}22 \% \text { MACE in CVO PCl and } 13 \% \text { in } \mathrm{CVI} \text {, } \\
\mathrm{p}=0.004\end{array}$ \\
\hline $\begin{array}{l}\text { Gershlick et al., } \\
2015^{22}\end{array}$ & CVLPRIT & 140 & 150 & N/A & $\mathrm{Ml}$, death, HF & 12 months & $\begin{array}{l}21 \% \mathrm{MACE} \text { in } \mathrm{CVO} \mathrm{PCl} \text { versus } 10 \% \text { in } \\
\mathrm{CVI}, \mathrm{p}=0.009\end{array}$ \\
\hline $\begin{array}{l}\text { Hamza et al., } \\
2016^{28}\end{array}$ & Multicentre & 50 & N/A & 50 & MI, death, TVR & 6 months & $\begin{array}{l}\text { 24\% MACE in CVO PCI versus } 6 \% \text { in } \\
\text { CVI-S, } p=0.01\end{array}$ \\
\hline $\begin{array}{l}\text { Thiele et al., } \\
2017^{27}\end{array}$ & CULPRIT-SHOCK & 344 & 341 & N/A & $\begin{array}{l}\text { Death, severe renal } \\
\text { failure }\end{array}$ & 30 days & $\begin{array}{l}45.9 \% \mathrm{MACE} \text { in } \mathrm{CVO} \mathrm{PCl} \text { versus } 55.4 \% \\
\text { in } \mathrm{CVI}, \mathrm{p}=0.01\end{array}$ \\
\hline $\begin{array}{l}\text { Smits et al., } \\
2017^{25}\end{array}$ & $\begin{array}{l}\text { COMPARE } \\
\text { ACUTE }\end{array}$ & 590 & 295 & N/A & $\begin{array}{l}\text { Death, MI, repeat } \\
\text { revascularization and } \\
\text { CVA }\end{array}$ & 12 months & $\begin{array}{l}20.5 \% \text { MACE in CVO PCl versus } 7.8 \% \text { in } \\
C V I, p<0.001\end{array}$ \\
\hline $\begin{array}{l}\text { Mehta et al., } \\
2019^{26}\end{array}$ & COMPLETE & 2,025 & N/A & 2,016 & Ml, CV death & 3 years & $\begin{array}{l}\text { 10.5\% MACE in CVO PCl versus } 7.8 \% \text { in } \\
\text { CVI-S, } p=0.004\end{array}$ \\
\hline
\end{tabular}

ACS = acute coronary syndrome; $C R=$ complete revascularization; $C V=$ cardiovascular; $C V A=$ cerebrovascular insufficiency; $C V I=$ complete multivessel intervention; $\mathrm{CVI}-\mathrm{S}=$ complete staged multivessel intervention; $\mathrm{CVO}=$ culprit vessel only; $\mathrm{HF}=$ heart failure; $\mathrm{MACE}=$ major adverse cardiac events; $\mathrm{MI}=\mathrm{myocardial}$ infarction; $\mathrm{N} / \mathrm{A}=\mathrm{not}$ applicable; $\mathrm{PCl}=$ percutaneous coronary intervention; TVR = total vascular revascularization.

clinically significant stenosis to be $\geq 50 \%$, other trials defined significant lesions as $\geq 70 \%$ stenosed. Perhaps the biggest limitation between these observational trials lies in the fact that no specific criteria were listed as to why operators chose between $\mathrm{CVO} \mathrm{PCl}$ and multivessel $\mathrm{PCl}$. Without knowing why decisions were made for one type of revascularization strategy versus another, it is difficult to apply the results of these studies to the general patient population.

\section{Randomized controlled trials}

More recently, there have been several randomized studies that have compared $\mathrm{CVO} \mathrm{PCl}$ to multivessel $\mathrm{PCl}$, either in a staged fashion or at the index event (Table 2). ${ }^{18-28}$ One of the earliest randomized controlled trials, published in 2004, studied revascularization rates between CVO and CVI in patients with STEMI. ${ }^{19}$ This was a single-centre trial involving 69 patients with STEMI who underwent either CVO (17 patients) or CVI-S (52 patients) during index hospitalization, and evaluated the need for repeat revascularization at 12 months. The need for repeat revascularization in the CVO group was numerically higher than in the CVI-S group, but not statistically significant (35 versus $17 \%, p=0.247$ ). At the same time, CVI could be achieved without higher complications or resource utilization during the index hospitalization. One could infer that CVI-S was safe and feasible at the index hospitalization, and there was a trend towards higher revascularization in the CVO group.

A single-centre Italian study randomized patients to CVO or CVI/CVI-S groups. ${ }^{18}$ Patients with cardiogenic shock, left main disease, previous coronary artery bypass graft and severe valvular heart disease were excluded. At a mean follow-up of $2.6 \pm 1.4$ years, higher rates of repeat revascularization, rehospitalization and in-hospital death were observed in the cohort who underwent CVO. Time-to-event analysis curves suggested lower MACE events in patients undergoing multivessel revascularization either as a staged procedure or at the index event. In the PRAMI trial, a group of investigators across five centres in the UK evaluated this question in 465 patients stratified to index multivessel $\mathrm{PCl}$ versus $\mathrm{CVO} \mathrm{PCl} .^{20}$ There was composite endpoint reduction in refractory angina, nonfatal $\mathrm{MI}$, repeat revascularization and cardiac death in patients undergoing $\mathrm{CVI}$. While the $\mathrm{CVI}$ procedures required higher contrast load and greater fluoroscopy times, complications were no different among the two cohorts, suggesting safety as well as efficacy of CVI in a STEMI cohort.

Contrasting results were seen with the PRAGUE-13 trial, where researchers compared patients who underwent CVO ( $n=108)$ with patients who underwent CVI-S ( $n=106)$ within 40 days following the index procedure. Composite endpoints of all-cause mortality, non-fatal $\mathrm{MI}$ and stroke were similar among the CVI-S versus CVO groups (16.0\% versus $13.9 \%, p=0.407){ }^{21}$ The difference in outcomes is postulated to have occurred based on the selectivity criteria of the patients, lower use of drug-eluting stents and exclusion of patients with angina pectoris 1 month prior to the index event. Similarly, researchers of the CVLPRIT trial studied 296 patients across seven sites in the UK in the same fashion, with the intention to look at composite endpoints of all-cause death, recurrent $\mathrm{Ml}$, heart failure and ischaemia-driven revascularization at 12 months. ${ }^{22}$ Primary endpoints occurred in $10 \%$ of the multivessel revascularization 
cohort versus $21.2 \%$ in the CVO group (hazard ratio $0.45,95 \%$ confidence interval $[\mathrm{Cl}] 0.24-0.84, p=0.009$ ). Kaplan-Meier curves showed early divergence of the two arms. Results were consistent across different sub-groups including women, the elderly (above age 65) and those with double vessel disease. The incidence of complications was also not significantly different between the groups.

While several randomized controlled trials suggested a potential benefit with CVI in STEMI, an important consideration is how to optimally select patients for non-infarct artery revascularization. The FAME-1 and DEFER trials suggested that fractional flow reserve (FFR)-guided revascularization of non-culprit vessels can potentially reduce the rate of revascularization compared with interventions determined by angiographic assessment alone. ${ }^{29,30}$ A small randomized controlled trial by Ghani et al. studied 121 patients with at least one non-culprit lesion, and randomized 80 patients to early FFR-guided $\mathrm{PCl}$ and 41 patients to medical treatment. ${ }^{23}$ At 3 years' follow-up, there was no significant difference between the groups in terms of all-cause mortality.

The recent DANAMI3-PRIMULTI multicentre trial also assessed FFR-guided multivessel $\mathrm{PCl}$ in a STEMI setting and demonstrated statistically significant lower MACE rates at 1 year in favour of multivessel FFR-guided PCl compared with CVO PCl. ${ }^{24}$ However, it was noted that the statistics were mainly driven by ischaemia-driven revascularization, as the results did not show any statistical significance when looking solely at all-cause mortality or nonfatal MI. An additional recent trial also tested the concept of FFR utilization when determining the need for complete revascularization in a STEMI setting. This study randomized 885 patients 1:2 for FFR-guided multivessel PCI versus CVO PCl. ${ }^{25}$ Composite MACE was lower in the FFR arm (7.8\% versus $20.5 \%, p<0.001$ ) and was primarily driven by the need for repeat revascularization.

Most recently, the COMPLETE trial, published in 2019, was the largest trial to-date looking at $\mathrm{CVO} \mathrm{PCl}$ versus multivessel revascularization. ${ }^{26}$ Patients with STEMI and multivessel disease who underwent successful CVO $\mathrm{PCl}$ were randomized to either complete revascularization or no further revascularization. Complete revascularization of non-infarct related arteries was performed if there was at least $70 \%$ stenosis of the vessel diameter on visual inspection, or 50-69\% stenosis with an FFR measure of $\leq 0.8$. The first co-primary endpoint was the composite of cardiovascular death or Ml. The second co-primary endpoint was the composite of cardiovascular death, MI or ischaemia-driven revascularization. After a median follow-up of 3 years, the first co-primary endpoint occurred in $7.8 \%$ of patients in the complete-revascularization group compared with $10.5 \%$ in the CVO PCl group ( $p=0.004)$. This result was driven by the lower incidence of new $\mathrm{MI}$ in the complete revascularization group than in the CVO $\mathrm{PCl}$ group (5.4\% versus $7.9 \%$ ). The second co-primary endpoint occurred in $8.9 \%$ of patients in the complete-revascularization group, compared with $16.7 \%$ in the CVO PCl group $(\mathrm{p}<0.001)$. Although this was a relatively large trial involving 4,041 patients, the study was met with criticism due to its inclusion of patients with a relatively low SYNTAX score for non-culprit lesions and exclusion of patients with cardiogenic shock. In addition, physicians could decide when to pursue staged revascularization as long as it was within 45 days of index procedure, further complicating the question of appropriate timing for multivessel revascularization.

Exploring the issue further, the FLOWER-MI trial (ClinicalTrials.gov identifier: NCT02943954), published in May 2021, assessed the utility of FFR for complete revascularization during STEMI, as opposed to the use of angiography-guided $\mathrm{PCl}^{31,32}$ Conducted in 41 centres in France, the trial randomized 1,171 patients who had undergone successful PCl of the infarct-related artery to either complete revascularization by FFR or angiography, with the second procedure performed within 5 days of initial procedure. The primary endpoint was a composite of death from any cause, nonfatal Ml or urgent need for additional stenting within 12 months. After 12 months, the primary composite endpoint occurred in $5.5 \%$ of patients in the FFR group and $4.2 \%$ in the angiography-guided group, with a non-significant value of $p=0.31$. Findings from this trial suggest that either a FFR-guided or angiography-guided strategy are acceptable choices in the management of complete revascularization $\mathrm{PCl}$ in the setting of STEMI.

\section{Revascularization in cardiogenic shock}

The majority of observational studies and randomized controlled trials excluded patients with cardiogenic shock. However, the CULPRIT-SHOCK trial attempted to examine this population specifically. The study was a prospective, European, multicentre, open-label, randomized trial involving 706 patients enrolled from 2013 to 2017, with a primary endpoint of all-cause death and severe renal failure within 30 days. ${ }^{33} \mathrm{CVO} \mathrm{PCl}$ was found to have a $9.5 \%$ absolute reduction in the primary endpoint, driven primarily by a $7.3 \%$ absolute reduction in all-cause mortality compared with $\mathrm{CVI} \mathrm{PCl}$. One major criticism of the study was its lack of longer duration follow-up. As a result, post-hoc analysis at 1-year follow-up was performed, which revealed that mortality did not differ significantly between $\mathrm{CVO} \mathrm{PCl}$ and the multivessel PCl group; death from any cause had occurred in 172 of 344 patients (50\%) and 194 of 341 patients (56.9\%), respectively (relative risk [RR] $0.88,95 \% \mathrm{Cl} 0.76-1.01$ ). However, the incidence of rehospitalization for heart failure was higher $(5.2 \%$ versus 1.2\%; RR increase $4.46,95 \% \mathrm{Cl} 1.53-13.04)$ and repeat revascularization was more frequent $(32.3 \%$ versus $9.4 \%$, RR increase $3.44,95 \% \mathrm{Cl}$ 2.39-4.95) with CVO PCl compared with multivessel PCl. However, this trial was only powered for a 30-day analysis. The 1-year outcomes examined in the post-hoc analysis need to be further studied and validated with adequate power to answer the hypothesis generated by the trial.

\section{Limitations of randomized controlled trials}

Although more heavily weighted than observational trials, these randomized controlled trials also had some limitations. Some randomized controlled trials have limited documentation on selection criteria regarding how non-culprit lesions were deemed suitable for $\mathrm{PCl}$, particularly the PRAMI and CVLPRIT trials. Other trials examined staged revascularization but failed to give optimal timing for reperfusion, which ranged from the index procedure up to 45 days after. Most trials, aside from the CULPRIT-SHOCK trial, avoided patients with cardiogenic shock. This is a particularly important limitation as patients with cardiogenic shock complicating MI are far more likely to have multivessel coronary artery disease. Lastly, sample sizes and statistical power to detect differences in death or repeat $\mathrm{Ml}$ were limited in most randomized controlled trials, except for the COMPLETE trial.

\section{Current guidelines}

Prior to recent observational studies and randomized controlled trials, older guidelines recommended against multivessel $\mathrm{PCl}$ in patients with STEMI. Non-infarct related artery (IRA) PCI was usually only considered in the context of abnormal findings on non-invasive testing, such as an abnormal nuclear stress test. ${ }^{34}$ These recommendations were likely based on issues of safety (longer procedural time, contrast nephropathy and higher risk of procedural complications) and prior observational studies which supported CVO PCl. However, the 2015 American College of Cardiology/American Heart Association/Society of Cardiovascular Angiography and Interventions guidelines released an 
Table 3: International guidelines recommendations for multivessel PCI in STEMI

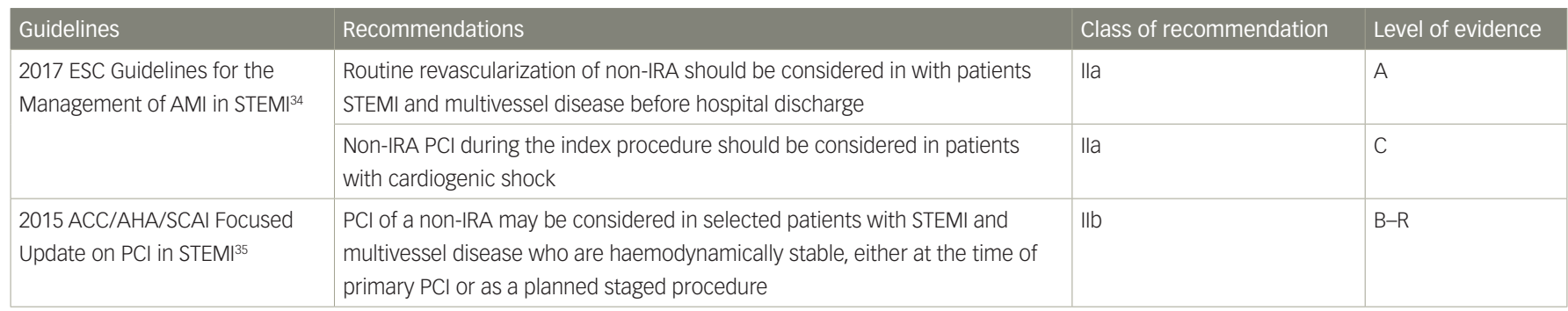

Class IIa, benefit >>risk; procedure is reasonable. Class III, benefit >risk; procedure may be considered. Class III, harm; procedure is not recommended. Level of evidence: $B$, data derived from single randomized trial or from large nonrandomized studies. $B-R$, moderate-quality evidence from one or more randomized controlled trials and/or meta-analyses of moderate-quality randomized controlled trials.

ACC $=$ American College of Cardiology; AHA = American Heart Association; AMI = acute myocardial infarction; EACTS= European Association for Cardio-Thoracic Surgery; ESC = European Society of Cardiology; IRA = infarct-related artery; PCI = percutaneous coronary intervention; SCAI = Society for Cardiac Angiography and Interventions; STEMI = ST-elevation myocardial infarction

updated Class IIb recommendation, stating that PCl of a non-IRA may be considered in selected patients with STEMI and multivessel disease who are haemodynamically stable, either at the time of primary PCI or as a planned staged procedure (Table 3). ${ }^{34,35}$ The 2015 document also commented that there was insufficient data at the time to inform a recommendation with regards to the optimal timing of non-IRA PCI. Meanwhile, the 2017 European Society of Cardiology (ESC) Guidelines for the Management of STEMI gives a Ila recommendation for consideration of routine revascularization of non-IRAs in patients with STEMI with multivessel disease before hospital discharge. ${ }^{36}$ In addition, the document gives a Ila recommendation for consideration of non-IRA $\mathrm{PCl}$ during the index procedure for patients with cardiogenic shock, although this is contradictory to the CULPRIT-SHOCK trial. Similar to the American guidelines, the ESC guidelines state that the most appropriate timing for non-IRA revascularization has not been well studied, and thus no recommendation in favour of immediate versus staged multivessel $\mathrm{PCl}$ can be given. Although no firm recommendations exist for routine multivessel revascularization in patients with STEMI, current guidelines do seem to reflect that revascularization of non-culprit vessels is an important factor for consideration at the time of the index procedure or hospitalization.

\section{Discussion}

Examination of the literature reveals increasing support for multivessel revascularization in patients with STEMI without cardiogenic shock, either at the index hospitalization or in a staged fashion. While previous observational data deemed multivessel intervention as counterintuitive and harmful, the literature continues to challenge some of our preconceptions regarding multivessel revascularization in patients with STEMI. Several studies now support multivessel intervention in this population, particularly in a staged fashion. This may be due to the known instability of non-culprit lesions in the setting of ACS and the diffuse coronary processes involved in ACS. Although older observational trials support $\mathrm{CVO} \mathrm{PCl}$, with the advent of newer technologies, evolving revascularization techniques, advanced equipment, and increasing operator experience, outcomes in multivessel $\mathrm{PCl}$ continue to improve.

Due to the availability of multiple randomized controlled trials and observational trials, several meta-analyses have been performed in the hopes of gaining further understanding of the most appropriate reperfusion strategies. In the last 2 years, there have been multiple meta-analyses that suggest potential benefits with multivessel revascularization in the setting of STEMI. ${ }^{37-40}$ Delving even further into the issues of multivessel revascularization at the time of STEMI, a meta-analysis performed by Li et al. compared CVI-S and CVI using 10 different studies (four randomized and six non-randomized). ${ }^{41}$ The results of the analysis revealed improved short- and longer-term survival with staged revascularization when compared with one-time complete revascularization.

While recent evidence suggests that revascularization of multivessel disease in patients with STEMI is an important consideration, it remains unclear whether these results will affect current practices. There remain several areas that continue to require additional investigations when considering revascularization of multivessel disease in patients with STEMI, such as the utility of non-invasive testing and FFR-based interventions. As a result, there are several ongoing trials, including the MULTISTARS AMI trial. ${ }^{42}$

\section{Conclusion}

Revascularization of multivessel disease in patients with STEMI has been an important issue of discussion and debate. While observational studies have provided a range of differing outcomes, recent randomized studies support multivessel revascularization in patients with STEMI without cardiogenic shock, either at the index hospitalization or as an early staged procedure. However, in patients with STEMI with cardiogenic shock, further investigations are still required to determine optimal reperfusion strategies. $]$
1. Park DW, Clare RM, Schulte PJ, et al. Extent, location, and clinical significance of non-infarct-related coronary artery disease among patients with ST-elevation myocardial infarction. JAMA. 2014;312:2019-27.

2. Soraja P, Gersh BJ, Cox DA, et al. Impact of multivessel disease on reperfusion success and clinical outcomes in patients on reperfusion success and clinical outcomes in patients
undergoing primary percutaneous coronary intervention for undergoing primary percutaneous coronary intervention for . acute myocardial ifarction. Eur Heart J. 2007,28.1709-16.

Toutouzas K, Drakopoulou M, Mitropoulos J, et al. Elevated plaque temperature in non-culprit de novo atheromatous lesions of patients with acute coronary syndrome. J Am Coll Cardiol. 2006;47:301-6.

4. Goldstein JA, Demetriou D, Grines $C L$, et al. Multiple complex coronary plaques in patients with acute myocardial infarction N Engl J Med. 2000;343:915-22.

5. Rioufol G, Finet G, Ginon I, et al. Multiple atherosclerotic plaque rupture in acute coronary syndrome: a three-vesse intravascular ultrasound study Circulation. 2002;106:804-8.

6. Parodi G, Mernisha G, Valenti R, et al. Five year outcome after primary coronary intervention for acute ST elevation myocardial infarction: results from a single centre experience. myocardial infarction. result

7. Jaguszewski M, Radovanovic D, Nallamothu BK, et at. Multivessel versus culprit vessel percutaneous coronary intervention in ST elevation myocardial infarction. is more worse? Eurolntervention. 2013:9:909-15.

8. Santos AR, Picarra BC, Celeiro M, et al. Multivessel approach in STelevation myocardial infarction: impact on inhospital morbidity and mortality. Rev Port Cardiol. 2014;33:67-73.

9. Iqbal MB, Ilsley C, Kabir T, et al. Culprit vessel versus multivesse intervention at the time of primary percutaneous coronary intervention in patients with ST segment elevation myocardia infarction and multivessel disease: real-world analysis of 3984 patients in London. Circ Cardiovasc Quality Outcomes. $2014 ; 7: 936-43$

10. Hannan EL, Samadashvili Z, Walford $G$, et al. Culprit vesse percutaneous coronary intervention versus multivessel and percutaneous coronary intervention versus multivessel and staged percutaneous coronary intervention for ST-segment lisease JACC Cardioisc Inter. 2010:322-31.

11. Abe D, Sato A Hoshi T et al Initial culprit-only versus initial multivessel percutaneous coronary intervention in patients with ST segment elevation myocardial infarction: results from the Ibaraki Cardiovascular Assessment Study registry. Heart Vessels. 2014;29:171-7.

12. Lee JM, Rhee TM, Hahn JY, et al. Multivessel percutaneous coronary intervention in patients with STEMI with cardiogenic shock. J Am Coll Cardiol. 2018:71:844-56. 
13. Cavender MA, Milford-Beland S, Roe MT, et al. prevalence, predictors, and in-hospital outcomes of non-infarct artery intervention during primary percutaneous coronary intervention for ST-segment elevation myocardial infarction (from the National Cardiovascular Data Registry). Am J Cardiol. (from the National $104: 507-13$.

14. Russo JJ, Wells GA, Chong AY, et al. Safety and efficacy of staged percutaneous coronary intervention during index admission for ST-elevation myocardial infarction with multivessel coronary disease (insights from the University of Ottawa Institute STEM Registry). Am J Cardiol. 2015;116:1157-62

15. Chen $\mathrm{HC}$, Tsai $\mathrm{TH}$, Fang $\mathrm{HY}$, et al. Benefit of revascularization in non infarct related artery multivessel disease patients with ST-segment elevation myocardial infarction undergoing primary percutaneous coronary intervention. Int Heart Journal. 2010;51:319-24

16. Toyota T, Shiomi H, Taniguchi T, et al. Culprit vessel-only vs. staged multivessel percutaneous coronary intervention strategies in patients with multivessel coronary artery disease undergoing primary percutaneous coronary intervention ST-segment elevation myocardial infarction. Circ 1 . 2016:80:371-8.

17. Manari A, Varani E, Guastaroba MS, et al. Long-term outcome in patients with ST segment elevation myocardial infarction and multivessel disease treated with culprit-only, immediate, or staged multivessel percutaneous revascularization strategies: insights from the REAL Registry. Catheter Cardiovasc Interv. 2014;84:912-22.

18. Politi L, Sgura F, Rossi R, et al. A randomized trial of target-vessel versus multivessel revascularization in ST-elevation myocardial infarction: major adverse cardiac events during long-term follow up. Heart. 2010:96:662-7.

19. Di Mario C, Mara S, Flavio A, et al. Single vs multivessel treatment during primary angioplasty: results of the multicentre randomized HEpacoat for cuLPrit or multivessel stenting for Acute Myocardial Infarction (HELPAMI) Study. Int I CardiovasC Acute Myocardial Infarction

20. Wald DS, Morris JK, Wald NJ, et al. Randomized trial of preventive angioplasty in myocardial infarction. N Eng/ J Med. 2013;369:1115-23

21. Hlinomaz O, Groch L, Polokova K, et al. Multivessel coronary disease diagnosed at the time of primary PCI for STEMI: complete revascularization versus co PRAGUE 13 trial. Kardiologicka revue. 2015;17:214-20.

22. Gershlick AH, Khan JN, Kelly DJ, et al. Randomized trial of complete versus lesion-only revascularization in patients undergoing primary percutaneous coronary intervention for STEMI and multivessel disease: the CVLPRIT trial. J Am Coll STEMI and multivessel dis

23. Ghani A, Dambrink JHE, Hof WJ, et al. Treatment of non-culprit lesions detected during primary PCl: long-term follow up of a randomized clinical trial. Neth Heart J. 2012;20:347-53.

24. Engstrøm T, Kelbæk H, Helqvist S, et al. Complete revascularization versus treatment of the culprit lesion only in patients with ST-segment elevation myocardial infarction and multivessel disease (DANAMI-3 - PRIMULTI): an open-label, randomized controlled trial. Lancet. 2015;386:665-71.

25. Smits PC, Abdel-Wahab M, Neumann FJ, et al. Fractional flow reserve guided multivessel angioplasty in myocardial infarction. N Engl J Med. 2017;376:1234-44.

26. Mehta SR, Wood DA, Storey RF, et al. Complete revascularization with multivessel PCI for myocardial infarction. N Eng// Med. 2019:381:1411-21.

27. Thiele H, Akin I, Sandri M, et al. PCI strategies in patients with acute myocardial infarction and cardiogenic shock. N Eng/ J Med. 2017;377:2419-32.

28. Hamza M, Mahmoud N, Elgendy IY. A randomized trial of complete versus culprit-only revascularization during primary percutaneous coronary intervention in diabetic patients wi acute ST elevation myocardial infarction and multi vesse disease. J Interv Cardiol. 2016;29:241-7.

29. Tonino PA, Bruyne BD, Pijls NH, et al. Fractional flow reserve versus angiography for guiding percutaneous coronary intervention. N Eng/ J Med. 2009;360:213-24.

30. Bech JW, Bruyne BD, Pijls NJ, et al. Fractional flow reserve to determine the appropriateness of angioplasty in moderate coronary stenosis. Circulation. 2001;103:2928-34.

31. Pumirat E, Cayla G, Simon T, et al. Multivessel PCl Guided by FFR or Angiography for Myocardial Infarction. N Engl I Med. 2021;385:297-308

32. ClinicalTrials.gov. FLoW Evaluation to Guide Revascularization in Multi-vessel ST-elevation Myocardial Infarction (FLOWER-MI). ClinicalTrials.gov Identifier: NCT02943954. Available at: https://clinicaltrials.gov/ct2/show/NCT02943954 (accessed 21 July 2021).

33. Levine GN, Bates ER, Blankenship JC, et al. 2011 ACCF/AHA SCAI guideline for percutaneous coronary intervention: a repo of the American College of Cardiology Foundation/American Heart Association Task Force on Practice Guidelines and the Society for Cardiovascular Angiography and Interventions.
Circulation. 2011;124:e574-651.

34. Ibanez B, James S, Agewall S, et al. 2017 ESC guidelines for the management of acute myocardial infarction in patients presenting with ST-segment elevation: the task force for the management of acute myocardial infarction in patients presenting with ST-segment elevation of the European Society presenting with ST-segment elevation of the Europe
of Cardiology (ESC). Eur Heart J. 2018;39:119-77.

35. Levine GN, Bates ER, Blankenship JC, et al. 2015 ACC/AHA SCAl focused update on primary percutaneous coronary intervention for patients with ST-elevation myocardia infarction: an update of the 2011 ACCF/AHA/SCA guideline for percutaneous coronary intervention and the 2013 ACCF/AHA guideline for the management of ST-elevation myocardial infarction: a report of the American college of Cardiology/American Heart Association Task Force on Clinical Practice Guidelines and the Society for Cardiovascular Angiography and Interventions. Circulation. 2016:133:1135-47.

36. Pavasini R, Biscaglia S, Barbato E, et al. Complete revascularization reduces cardiovascular death in patients with ST-segment elevation myocardial infarction and multivessel disease: systematic review and meta-analysis of randomized clinical trials. Eur Heart J. 2019;41:4103-10.

37. Osman M, Khan SU, Farjo PD, et al. Meta-analysis comparing complete versus infarct-related artery revascularization in patients with ST elevation myocardial infarction and multivesse coronary disease. Am I Cardiol. 2020;125:513-20.

38. Salih M, Ibrahim AM, Al-Akchar M, et al. Complete versus culprit only revascularization in patients presenting with S segment elevation myocardial infarction: a meta-analysis of randomized control trials. Cardiovasc Revasc Med. 2020;21:1482-8

39. Atti V, Gwon Y, Narayanan MA, et al. Multivessel versus culprit-only revascularization in STEMI and multivessel coronary artery disease: meta-analysis of randomized trials. coronary artery disease: meta-analysis of

40. Li Z, Zhou Y, Xu Q et al. Staged versus one-time complete revascularization with percutaneous coronary intervention in STEMI patients with multivessel disease: a systemic review and meta-analysis. PLoS One. 2017;12:e0169406.

41. ClinicalTrials.gov. MULTivessel Immediate Versus STAged Revascularization in Acute Myocardial Infarction -The MULTISTARS AMI Trial (MULTISTARS AMI). ClinicalTrials.gov Identifier: NCT03135275. Available at: https://clinicaltrials.gov/ ct2/show/NCT03135275 (accessed 21 July 2021). 